Research, Society and Development, v. 7, n. 7, p. 01-28, e1577360, 2018

ISSN 2525-3409 (CC BY 4.0)

\title{
Práticas acadêmicas integradas e transdisciplinares como meio do desenvolvimento crítico e autoral do bacharelando em Direito
}

\section{Integrated and transdisciplinary academic practices as a means of critical and authorial development of the Bachelor of Laws}

Shirlei Luana Chaves e Sousa Pereira

Fundação Comunitária de Ensino Superior de Itabira-Funcesi, Brasil

E-mail: shirlei.pereira@ funcesi.br

Recebido: 18/04/2018 - Aceito: 02/05/2018

\begin{abstract}
Resumo
$\mathrm{O}$ artigo tem como objetivo investigar formas de promover, por meio de práticas integradas e transdisciplinares, capacidades de leitura e escrita do domínio acadêmico do futuro bacharel em Direito. Para tanto, propusemos uma pesquisa-ação que nos permitiu, a partir de procedimentos envolvendo observação, entrevistas com grupo focal e questionário, traçar uma agenda de trabalho de modo a alterar nossa forma de didatização em sala de aula. O diálogo entre os professores do curso de Direito constituiu-se também como essencial, pois possibilitou práticas interdisciplinares e multidisciplinares que levassem os acadêmicos a agenciar modos de leitura e produção textual acadêmica que fossem efetivamente reflexivas, significativas e coletivizadas. Assim, as atividades desenvolvidas pelos alunos permitiram revelar em que medida um trabalho processual e interdisciplinar auxilia na ampliação de capacidades discursivo-textuais, bem como os processos de didatizar, sob perspectiva social e interacionista, podem permitir um crescimento crítico e autoral do acadêmico.
\end{abstract}

Palavras-chave: Letramento acadêmico; Gêneros textuais; Práticas transdisciplinares.

\begin{abstract}
The article aims to investigate ways of promoting, through integrated and transdisciplinary practices, reading and writing skills of the academic field of the future bachelor in Law. To do so, we proposed an action research that allowed us, from procedures involving observation, interviews with focus group and questionnaire, to draw up a work agenda in order to change our form of classroom literacy. The dialogue among the professors of the Law course was also essential, as it allowed for interdisciplinary and multidisciplinary practices that would lead the academics to work in ways of reading and academic textual production that were effectively reflective, meaningful and collectivized. Thus, the activities developed by the students allowed to reveal to what extent a process and
\end{abstract}


interdisciplinary work assists in the expansion of discursive-textual capacities, as well as the processes of learning, under a social and interactionist perspective, can allow a critical and authorial growth of the academic.

Keywords: Academic writing; Textual genres; Transdisciplinary Practices

\section{Introdução}

O ensino superior necessita de uma didática capaz de reorientar as práticas de leitura e escrita acadêmicas, geralmente concentradas na disciplina Língua Portuguesa, visto que alguns acadêmicos chegam à universidade apresentando dificuldades de expressão verbal, especialmente de produção escrita, o que constitui um dilema, pois futuros profissionais do Direito precisam apresentar proficiência em suas atividades de linguagem, tendo em vista a participação dos mesmos nas reflexões sociais.

Identificada essa necessidade, a partir da minha experiência como professora de Língua Portuguesa no primeiro período do curso de Direito, surgiu a proposta de uma agenda de atividades que colaborasse para o posicionamento do aluno como sujeito-agente nos processos discursivos, isto é, para a participação em práticas letradas do universo acadêmico de modo autônomo e autoral. Para isso, propus uma revisão didática das práticas de leitura e escrita de textos acadêmicos, a fim de estabelecer maneiras que auxiliassem os alunos a operar com a língua em uso.

O ensino dos gêneros discursivos, como resenha temática, resumo, diário de leituras, artigo de opinião e debate, possibilitou, a partir do quadro teórico-metodológico do Sociointeracionismo, o desenvolvimento de práticas leitoras e escriturais que contribuíssem tanto para análise dos textos dos acadêmicos, como para a evolução da sua produção textual. Isso porque o referido princípio epistemológico atrela o desenvolvimento da condição linguística aos processos enunciativos que envolvem as práticas textuais, especialmente na instância escolar. Alguns estudos como o de Bronckart (2006) nos mostram como as práticas de produção textual em uma perspectiva discursiva e interacionista contribuem para o desenvolvimento do aluno, pois o sujeito produtor se encontra em uma "situação de ação de linguagem" em que acionará representações necessárias para a sua produção textual, sendo elas:

a) as representações referentes ao quadro material ou físico da ação [...]; b) as representações referentes ao quadro sociossubjetivo da ação verbal $[\ldots] ;$ c) as outras representações referentes à situação e também os conhecimentos disponíveis no agente, referentes à temática que será expressa no texto. (BRONCKART, 2006, p. 146). 
Essas representações que o aluno constrói no processo da produção textual de viés discursivo e interacionista possibilita um olhar crítico a respeito do próprio texto, pois além de acionar seu conhecimento pessoal, em que busca o gênero que corresponde às representações de seu novo texto, ele também tem que adaptar o gênero às particularidades de sua produção textual.

Outro aspecto importante abordado por Bronckart (2006) é o da arquitetura textual, cuja estrutura se divide em três níveis: a infraestrutura (tipos de discursos), a coerência temática (conexão, coesão nominal e verbal) e a coerência pragmática (gestão de vozes e modalizações). Esses três níveis é que dão corpo e sentido ao texto, pois o aluno precisa planejar o "conteúdo temático" para, posteriormente, delimitar sua coerência, por meio de "mecanismos de textualização" e, em seguida, utilizar elementos de modalização e mecanismos de enunciação que alcancem a instância de seus objetivos para aquele texto. Ao trabalhar com o quadro de Bronckart nas aulas, notamos que a proposta de abordagem textual do estudioso contribuiu de forma significativa para o desenvolvimento discursivo e linguístico do acadêmico, pois exigiu a reorientação de competências e de capacidades que ele talvez já possuísse, mas não sabia como utilizar.

Ter conhecimento desses estudos de perspectiva social e interacionista é muito importante para nós, docentes, pois o gênero textual, nessas abordagens, é considerado como um instrumento de desenvolvimento que possibilita ao locutor agir socialmente e refletir sobre a própria ação. Por isso, repensei a minha didática, de forma a buscar novas metodologias que pudessem ampliar as habilidades de compreensão e produção textual. Conforme salientam Santos e Seixas:

Descrever e analisar gêneros textuais supõe tomá-los nas práticas em que são gerados, no acontecimento que permite suas condições de emergência; em uma palavra, e para falar em termos metafóricos, nas faíscas, nas centelhas produzidas pelo encontro (confronto, reencontro) de textualidades e subjetividades. (SANTOS; SEIXAS, 2012, p.6).

Pensar em um trabalho com gêneros é mostrar o desenvolvimento da linguagem em práticas sociais, pois eles são gerados a partir de condições e exigências do contexto, gerando uma dialogicidade entre o sujeito escritor e o seu texto. Nessa perspectiva, a arquitetura textual proposta por Bronckart (2006) nos permitiu compreender a composição dos textos de modo a orientar a atividade de ensino, tendo em vista os objetivos das práticas letradas e, consequentemente, o desenvolvimento de habilidades de leitura e escrita.

Antes de desenvolver essa pesquisa, pude perceber como docente que os textos que 
traziam posicionamento autoral ao longo do processo argumentativo e defesa de pontos de vista pareciam não pertencer ao universo letrado dos estudantes antes do ingresso à universidade, o que dificultava o processo de compreensão e produção de textos que lhes eram demandados. Outra dificuldade consistia na articulação de conhecimentos e de posicionamentos diante da leitura, como, por exemplo, na elaboração de resenhas críticas ou temáticas, artigos de opinião ou até mesmo na leitura e interpretação das leis. Nesse sentido, faltavam-lhes habilidades que possibilitassem a eles concretizar as práticas textuais dessa nova esfera - a acadêmica.

Sendo assim, a ausência dessas práticas letradas contribuía ainda mais para as dificuldades que os alunos encontravam na atividade com os textos acadêmicos. Conforme Machado, Lousada e Abreu-Tardelli (2004), quando os alunos são obrigados a ler e produzir textos da esfera acadêmica, demonstram muita dificuldade e expressam até mesmo certa desmotivação, o que muitas vezes leva alguns à desistência do curso.

Visou-se com a pesquisa aqui desenvolvida possibilitar aos universitários o domínio de práticas discursivas, especialmente as atreladas ao universo acadêmico. O desenvolvimento deste trabalho de investigação buscou compreender os alunos informantes como sujeitos socioistórico e ideologicamente situados. Portanto, não os pensamos fora de um contexto sociointeracionista. Logo, o nosso trabalho levou em consideração o meio social em que o aluno vivia, pois, de acordo com Bakhtin/Volochinov (1995, p.121), "o centro organizador de toda enunciação, de toda expressão, não é interior, mas exterior: está situado no meio social que envolve o indivíduo".

Para desenvolvermos essa pesquisa, tivemos como base, além da experiência desta pesquisadora ao longo de um ano e meio de docência, a observação da prática de leitura e produção de gêneros acadêmicos da área do Direito, conduzidas por professores de outras disciplinas, com alunos do $1^{\circ}$ período do curso de Direito do $1^{\circ}$ semestre de 2013 . Essas práticas tiveram como finalidade compreender as dificuldades dos alunos no que diz respeito à leitura e produção textual.

Para conhecermos as dificuldades e necessidades do aluno, foi aplicado um questionário socioeconômico em que buscamos conhecer a sua formação inicial até a universidade, especialmente os aspectos relacionados à leitura e escrita, bem como as expectativas ligadas às práticas textuais na esfera acadêmica. Os dados analisados nos levaram a desenvolver uma agenda de atividades que fosse capaz de aprimorar as habilidades de leitura e produção textual dos gêneros acadêmicos. Essas análises e a experiência vivenciada na disciplina de língua portuguesa nos motivaram a elaborar uma proposta didática 
voltada para o aperfeiçoamento das habilidades de leitura e produção textual dos alunos.

Sabe-se que profissionais do Direito envolvem-se diretamente com práticas de interpretação e produção dos mais diversos gêneros textuais que abarcam o mundo jurídico. Contudo, alguns profissionais se perdem em meio a essas práticas letradas, pois, de algum modo, não as desenvolveram durante o seu percurso acadêmico. Assim, o questionamento que norteou este trabalho foi: como elaborar uma metodologia de trabalho com leitura e produção de textos que leve de fato ao desenvolvimento letrado dos estudantes ingressantes no curso de Direito?

A partir deste questionamento começamos a pensar nas atividades em torno de textos sob a seguinte premissa: o desenvolvimento dos processos de interpretação e produção textual na esfera acadêmica vai muito além das aulas de língua portuguesa. Assim, é possível dizer que o letramento universitário é resultado de um trabalho que envolve todas as disciplinas e seus professores. Desse modo, consideramos que, a partir do momento em que os professores dialogarem entre si e buscarem desenvolver trabalhos em conjunto que promovam o domínio dos recursos textuais e discursivos, de forma a estimular o aluno nas mais variadas práticas discursivas, será possível ao discente ampliar suas habilidades de textualização, tanto escritas quanto orais.

Portanto, a nossa proposta foi buscar, por meio da multidisciplinaridade, desenvolver e ampliar as práticas de letramento universitário partindo da hipótese de que há uma relação entre os modos de orientação de cada professor em sua disciplina com o desenvolvimento das habilidades de leitura e produção textual. Além disso, pensamos que a mudança de metodologia, à luz de uma abordagem interacionista e sociodiscursiva de desenvolvimento, possibilitaria uma transformação nos modos como os estudantes compreendem e usam a língua e a linguagem na própria formação profissional. Nesse sentido, a metodologia de trabalho orientada pelas práticas textuais, no curso de Direito, deveria ser capaz de ampliar as capacidades dos estudantes no que se refere às habilidades de leitura e escrita, especialmente as que se efetivam com os gêneros textuais do âmbito acadêmico e jurídico.

Nesse viés, objetivou-se com esse trabalho investigar formas de promover, por meio de práticas integradas e transdisciplinares, as capacidades de leitura e escrita do futuro bacharel em Direito. Procurou-se a identificação das principais dificuldades que os alunos enfrentavam no processo de interpretação e produção de textos jurídicos; elaborar/propor meios didáticos que promovessem o desenvolvimento discursivo e linguístico dos alunos e compreender as barreiras que os impediam de desenvolver práticas de letramento acadêmico, tendo em vista o contexto social em que estavam inseridos e as atividades propostas pelos 
professores do curso de Direito.

É importante deixar claro que a pesquisa foi desenvolvida em um semestre. Nesse curto espaço de tempo era necessário preservar a programação prevista para cada disciplina. Sob esse viés, deparamo-nos com percalços comuns, como estranhamentos e surpresas que perpassam uma investigação aplicada, uma vez que esta demanda a participação e a disponibilidade de tempo de alunos e professores. Contudo, preciso ressaltar que os professores foram muito cooperativos, bem como a coordenação, direção e alunos. Essa pesquisa só foi possível pela estrutura concedida pela instituição para desenvolvê-la. Cabe salientar que não temos a pretensão de que este trabalho se torne um manual a ser seguido, afinal, trata-se de uma pesquisa inicial em que ainda há muitas lacunas, falhas e fissuras.

\section{Metodologia}

A escolha do corpus justifica-se pelas dificuldades encontradas nos processos envolvendo a leitura e a produção textual na esfera acadêmica. Tal esfera tem o propósito de formar sujeitos capazes de interagir com o mundo e ingressar em uma profissão. No que tange ao âmbito do Direito, produzir um texto exige muito mais que conhecimento teórico, exige habilidade e capacidade de se expressar de forma clara e objetiva, apresentando capacidade argumentativa e posicionamento crítico.

Várias são as peças processuais que o profissional do Direito precisa produzir e, para isso, precisa saber como construí-las. Assim, espera-se que haja uma mudança da prática didática no ensino superior, já que as defasagens quanto às capacidades letradas são gritantes e há uma forte expectativa por parte de alguns estudantes quanto ao aperfeiçoamento de suas habilidades. Além disso, observou-se em sala de aula, nos primeiros dias, uma expectativa dos alunos diante do fato de que as falhas que eles carregam desde a sua formação inicial sejam, de alguma maneira, sanadas no ensino superior. Essa observação só foi possível por desenvolvermos uma pesquisa-ação aplicada, ou seja, uma pesquisa que é desenvolvida efetivamente in loco. Para Barbier (2007, p.78), a pesquisa desenvolvida in loco apresenta cinco dimensões: “contrato, participação, mudança discurso e ação que constituem uma porta de entrada à ação para os pesquisadores. Passando da postura de pesquisador experimentalista até a da pesquisa-ação".

Assim, acreditamos que este trabalho se fez relevante para o curso de Direito, pois apresenta um caráter investigativo e interventivo, o qual possibilitou compreender as dificuldades de interpretação e produção textual enfrentadas pelo aluno e de que modo 
poderia superá-las. Cremos que a utilização de metodologias de coleta por meio de discursos dos alunos e dos professores colaborou para o desenvolvimento de uma proposta didática que tornasse os alunos capazes de desenvolver práticas discursivas que promovessem a autonomia autoral e a atitude crítica, capacitando-o não só para a participação no universo acadêmico, mas também, futuramente, no campo de sua atuação profissional.

A pesquisa foi desenvolvida com alunos do $1^{\circ}$ período do curso de Direito de uma fundação de ensino universitário de um município do interior de Minas Gerais.

$\mathrm{Na}$ fase inicial da pesquisa, tivemos 20 alunos como colaboradores. Eles foram escolhidos a partir da aplicação de um questionário e de uma observação em sala de aula que levou em consideração os seguintes aspectos: as habilidades apresentadas pelo aluno, bem como a sua vontade de aprender e a frequência às aulas.

Todos os 56 alunos da turma responderam ao questionário, mas apenas 36 se mostraram dispostos a participar da pesquisa. Entre os 36, avaliamos os questionários e selecionamos 20 para que fossem os sujeitos da pesquisa. No decorrer do semestre, 4 alunos que participavam da pesquisa desistiram do curso, assim, ficamos com 16. No transcorrer das aulas do semestre, à medida que as atividades iam sendo desenvolvidas, alguns estudantes foram se ausentando ou deixando de entregar as propostas de textos, demonstrando, em alguns casos, um desinteresse pelas atividades, o que nos levou a propor uma entrevista participante.

A ideia da entrevista em grupo se deu por permitir uma maior proximidade com os alunos e a socialização de questões relacionadas ao processo das vivências com a leitura e a escrita, dentro e fora da academia. Para a entrevista em grupo, assim procedemos: reunimonos por aproximadamente uma hora com cada grupo dos cinco escolhidos para participar da entrevista. Cada uma das sessões das entrevistas teve a professora pesquisadora (PP) como mediadora. No início da entrevista em grupo, a PP orientou como seria desenvolvida a entrevista, bem como salientou a colaboração e participação dos sujeitos informantes. Para provocar as reflexões e discussões, a PP apresentou aspectos e questionamentos acerca das práticas de didatização desenvolvidas no decorrer do semestre, na disciplina de Língua Portuguesa - Produção Textual.

Em seguida, foi aberto espaço para que os alunos falassem, o que ocorreu sem dificuldades, visto que os integrantes se mostravam motivados a debater sobre as questões propostas.

Após a realização da entrevista em grupo, houve dificuldade para selecionar os alunos que participariam das demais atividades propostas pela investigação, tendo em vista a riqueza 
dos dados coletados. Foram escolhidos, então, cinco alunos, cuja seleção levou em conta o interesse em participar da pesquisa, suas dificuldades e vontade de aprender, a frequência às aulas e a participação no trabalho interdisciplinar.

Como já foi mencionado, a nossa pesquisa, por ser estruturada pela pesquisa ação, implicou uma ação intervencionista e participante, tendo em vista a natureza dos processos interacionais e dos materiais discursivos gerados. Assim o pesquisador assume a postura de participante direto no meio em que irá desenvolver a pesquisa. Nesse aspecto, por ser implicada diretamente à ação da professora-pesquisadora e submetida a constantes reavaliações e alterações da prática didática no desenvolvimento das atividades, a pesquisa demandou a utilização de vários materiais e métodos de coleta, tais como: diário de campo, análises de materiais recolhidos, registros de áudio, etc. Nesse viés, a pesquisa-ação, para Barbier, apresenta-se como espiral em suas respectivas fases:

de planejamento, de ação, de observação e de reflexão, depois um novo planejamento da experiência em curso. $\mathrm{O}$ rigor da pesquisa-ação repousa na coerência lógica empírica e política das interpretações propostas nos diferentes momentos da ação. (BARBIER, 2007, p.60).

A coleta dos dados foi desenvolvida no $1^{\circ}$ semestre de 2013. Usamos a metodologia de observação direta que implicou uma análise prolongada de situações e comportamentos dos alunos. A observação direta possibilitou o contato com os informantes, visto que, como pesquisadora e docente da disciplina de Língua Portuguesa, tive essa proximidade com os alunos que fizeram parte da pesquisa. Inicialmente, utilizamos também o diário de campo, gênero textual que nos permitiu descrever e compreender as situações em que o aluno apresentava dificuldades, considerando-se a perspectiva qualitativa da pesquisa.

Pretendeu-se examinar globalmente o processo de elaboração das produções textuais que os alunos desenvolveram ao longo do semestre, bem como as atividades multidisciplinares com outros professores: seminário, debates, resenhas e análises críticas. Foram essas atividades que permitiriam ao aluno se desenvolver textualmente, e, ao pesquisador, obter o máximo de informações necessárias que pudessem contribuir para o levantamento e a análise dos dados e, consequentemente, para um trabalho de intervenção que possibilitasse o desenvolvimento de práticas letradas no âmbito universitário.

A análise dos dados obtidos foi feita de forma gradual e processual e nos deu pistas para avaliar as variações encontradas em todas as atividades desenvolvidas pelos alunosinformantes.

Nesse sentido, a pesquisa teve como foco atividades e ações de linguagem 
desenvolvidas pelos alunos e pelos professores. As atividades foram propostas conforme a perspectiva social e interacionista de Bronckart (1999, p. 31), em que a atividade de linguagem é coletiva ou "social" e a ação de linguagem "constitui uma unidade psicológica". A análise dos dados teve como base os pressupostos do Interacionismo Sociodiscursivo, pois "a ação constitui o resultado da apropriação, pelo organismo humano, das propriedades da atividade social mediada pela linguagem" (BRONCKART, 1999, p.42) e das práticas de letramento universitário.

Assim, podemos dizer que as ações dos alunos em sala de aula foram resultado de uma prática social anterior ao ingresso na universidade. Desse modo, podemos afirmar que, para o Interacionismo Sociodiscursivo, o que é externo ao contexto da sala de aula é imprescindível para a compreensão e análise dos dados, por isso a aplicação do questionário.

Ainda de acordo com Bronckart $(1997,1999)$, é necessário seguir quatro parâmetros quando se analisam ou produzem discursos: o lugar em que se produz o discurso, o emissor , o receptor e, é claro, o momento de produção, tendo também que levar em consideração o contexto sociossubjetivo que abarca o lugar social, o papel social do enunciador e do destinatário, o objetivo e o conteúdo temático.

Nesse viés, percebemos que, no momento de análise dos dados, foi de extrema importância pensar o aluno vinculado a sua "externalidade social”, pois as nossas ações de linguagem medeiam o social que, para Bronckart (1997, p. 13), são capacidades de ação e intenção - poder fazer e querer fazer. Ou seja, o ser humano, ao se comunicar por meio da fala ou da escrita, desenvolve ações que demonstram a sua intenção e, ao mesmo tempo, a sua vivência e a forma como é influenciado por ela.

Guiada por uma perspectiva qualitativa de investigação, buscamos Minayo (2007, p. 21), para quem "a pesquisa qualitativa trabalha com o universo dos significados, dos motivos, das aspirações, das crenças, dos valores e das atitudes”, os quais, segundo a autora, fazem parte da realidade humana. E foi essa realidade humana que deu sentido à nossa pesquisa. Desse modo, reafirmamos a orientação sociointeracionista de nosso trabalho, pois, como afirma Bronckart (1997, p. 13), “ações situadas cujas propriedades estruturais e funcionais são, antes de mais nada, um produto da socialização", ou seja, toda ação advém de um processo social, construindo-o e sendo responsável por ele.

Também buscamos orientação na perspectiva da pesquisa-ação, uma vez que tivemos uma participação reflexiva, a qual se fundamenta em um processo de intervenção de forma a obter uma mudança favorável no âmbito do ensino/aprendizagem. Esse tipo de pesquisa nos permitiu a interação com a nossa investigação por meio de ações. Nesta proposta, a relação 
entre teoria e prática foi de extrema importância, uma vez que a nossa atuação sobre a realidade que estudamos foi imprescindível.

Para Barbier (2002, p. 91), o pesquisador “deve combinar a organização, a informação, a energia, a retroação, as fontes, os produtos e os fluxos, input e output, do sistema, sem fechar-se numa clausura para onde o leva geralmente seu espírito teórico", ou seja, o pesquisador precisa ser cauteloso com a análise dos dados sem deixar influenciar-se por uma posição pessoal fechada que possa levar a uma pré-conclusão. Isso não implica que o pesquisador não possa fazer inferências, pelo contrário, elas são importantes, pois possibilita descobrir o que está por trás dos dados coletados, indo além do que está explícito. De acordo com Minayo (2007, p. 307):

Os pesquisadores que buscam a compreensão dos significados no contexto da fala, em geral, negam e criticam a análise de frequência das falas e palavras como critério de objetividade e cientificidade e tentam ultrapassar o alcance meramente descritivo da mensagem, para atingir, mediante inferência, uma interpretação mais profunda.

Seguindo esse viés, nota-se que os pesquisadores não estacionam nos limites do dizível, ao contrário, eles buscam estabelecer uma compreensão mais profunda. Para tal, precisamos dizer que se fez necessário compreender o contexto do qual faziam parte os sujeitos de análise. Pensar em contexto, de acordo com Lopes:

É saber que dimensão do contexto considerar. Primeiramente, convém precisar o aspecto relativo à pertinência do contexto, levando em conta que os elementos contextuais se mostram sob a forma de saberes e representações. Nessa perspectiva, contexto é um "conjunto de representações" que os interlocutores têm do próprio contexto, incluindo, portanto, o componente "participantes". (LOPES, 2004, p.7).

Desse modo, compreender o contexto é poder compreender as representações que são feitas pelos sujeitos que ali estão inseridos. E essa compreensão foi muito importante para nós, pois, no processo de análise, foi possível perceber que o aluno, no momento de sua produção, era influenciado pelo contexto socioistórico. O seu dizer tinha uma origem, uma influência.

Cabe salientar que a pesquisa-ação implica uma ação educativa que, de acordo com Oliveira (1981, p. 19), estabelece "o conhecimento da consciência e também a capacidade de iniciativa transformadora dos grupos com quem se trabalha". Nesse aspecto, afirmamos que trabalhar com a pesquisa-ação também foi muito importante para podermos conhecer de perto as demandas textuais e discursivas dos alunos e podermos atuar de forma efetiva na superação das dificuldades. 


\section{Resultados}

Vamos aqui, de forma breve, proceder ao relato sobre os sujeitos informantes e a relação deles com o universo acadêmico. Vamos abordá-los individualmente, já que as práticas de interação social desses sujeitos não são as mesmas.

Iniciarei pelo informante que denominamos de "A". "A" tem 33 anos, sua profissão é auxiliar de professor e doméstica. Essa aluna cursava a disciplina Língua Portuguesa Produção Textual, sob minha regência, pela segunda vez, pois, no $2^{\circ}$ semestre de 2012 , fora reprovada. As dificuldades relativas à leitura, interpretação e produção textual eram nítidas e, apesar do processo de investimento em atividades textuais, "A" não conseguiu vencê-las.

No primeiro dia de aula do semestre de aplicação da pesquisa, a acadêmica me procurou e disse que, apesar de sua dificuldade, não iria desistir do curso, pois era seu sonho e queria saber como eu poderia ajudá-la. Foi então que lhe contei sobre a pesquisa a ser feita, pela qual se mostrou muito interessada. Nesse momento, a aluna relatou sua dificuldade de ler os textos que os professores pediam, que não compreendia o que era dito em sala de aula e que na hora das provas não conseguia escrever.

Relatou que estava assustada com o curso, mas que mesmo assim iria cursá-lo, o que de fato ocorre. Sendo assim, é possível dizer que o letramento acadêmico não vinha se desenvolvendo, na realidade e, quando passou a acontecer, "A" enfrentou grandes dificuldades, sem, contudo, desistir, pois viu que era capaz de se desenvolver e compreender os gêneros textuais da esfera acadêmica. Notamos que ela precisava de que nós, professores, a orientássemos e a ajudássemos com os modos de elaboração dos textos acadêmicos.

Vamos agora falar um pouco de "E". "E" tem 49 anos e trabalha como técnica de enfermagem. Essa aluna ficou muito tempo sem estudar e concluiu o $2^{\circ}$ grau em 2002; essa interrupção dos estudos parece ter contribuído para as suas dificuldades.

Desde o primeiro dia de aula quando foi perguntado: Quais são as maiores dificuldades que vocês acham que têm com relação à Língua Portuguesa? "E” me respondeu: "Produzir um texto, não consigo passar para o papel o que eu penso". Foi então que "E" nos chamou a atenção, pois verbalizou sua dificuldade sem se sentir constrangida, já que o restante da turma ficou receoso em responder.

Na segunda semana de aula, a acadêmica nos procurou muito aflita porque não estava entendendo nada do que os professores estavam ministrando nas disciplinas e que não conseguia ler os textos indicados na graduação.

Mais uma vez, percebemos que era necessário (re) pensar em algo para colaborar 
academicamente com aqueles alunos. Naquele momento, ficava mais claro que o não conhecimento das práticas letradas do âmbito acadêmico torna muito dolorosa a aquisição de novas aprendizagens e, consequentemente, dificulta o processo de interação no ingresso à universidade.

Passaremos agora para a aluna "G". "G” tem 18 anos e é estudante. Concluiu o $2^{\circ}$ grau em 2012, portanto, assim que se formou no ensino médio, passou no vestibular para o curso de Direito. "G" era uma aluna que sempre pedia indicações de livros para ler e sugestões de como proceder com a leitura dos textos acadêmicos.

O próximo aluno é o "P", que tem 30 anos e trabalha como encarregado de transporte. No semestre anterior também havia sido reprovado em minha disciplina e em outras. $\mathrm{Na}$ época da pesquisa, estava cursando a minha disciplina pela $2^{\circ}$ vez. "P" sempre apresentou dificuldades e, por ser um aluno mais introvertido, não interagia com os colegas. Sentava sempre no fundo da sala e conversava baixo. Na primeira semana de aula, sugeri a ele que se sentasse na frente, mas não aceitou a sugestão. Depois de muito conversar com "P" ele passou a se sentar mais no meio da sala. Não fazia perguntas e nem participava das aulas, mas sempre entregava os trabalhos.

Outro sujeito informante da nossa pesquisa foi "R". "R" tem 32 anos e trabalha como policial militar, tendo concluído o ensino médio em 1998. "R" sempre foi um aluno frequente e participativo nas aulas. Contudo, conforme relatos dele, ter ficado sem estudar durante quinze anos foi algo que prejudicou o seu rendimento em sala de aula. Constantemente o acadêmico nos procurava para esclarecer algumas dúvidas e solicitava leituras complementares.

Observe-se que temos cinco alunos com perfis diferentes, mas, no que diz respeito ao universo acadêmico, apresentam a mesma dificuldade: leitura e compreensão dos textos acadêmicos, bem como a sua produção escrita. Então, foi a partir dessas dificuldades que alterei a minha didática em sala de aula.

A seguir, apresento os instrumentos utilizados, tendo em vista a metodologia escolhida para o desenvolvimento da intervenção didática que possibilitaria transformar os modos de fazer e agir relativamente à prática textual, na graduação.

Passamos a descrever e detalhar como foram realizados os trabalhos de intervenção em sala de aula.

No primeiro dia de aula, antes mesmo de falarmos sobre a pesquisa, solicitamos que os alunos desenvolvessem uma produção textual para que pudéssemos fazer um mapeamento de suas dificuldades. Ao solicitar essa $1^{\mathrm{a}} \mathrm{PT}$, não explicitamos quais deveriam ser as condições 
de produção. Assim, não foi dito qual gênero e nem a temática que deveria ser abordada pelos alunos. Ficou a critério de cada um a escolha do tema e do gênero. A elaboração do texto deuse em sala de aula e foi entregue no mesmo dia.

Nesse aspecto, tivemos as seguintes condições de produção:

Produção textual, a partir de solicitação da professora, no $1^{\circ}$ dia de aula, sem indicação de tema ou gênero.

Lugar social de onde se fala: ingressantes do $1^{\circ}$ período do curso de Direito

Função social do locutor: aluno do $1^{\circ}$ período do curso de Direito

Função Social do interlocutor: professora de Língua Portuguesa

Objetivos da interação verbal: identificar as dificuldades no processo de produção textual.

A 2 2 PT solicitada foi o resumo do conto "Pai contra mãe" de Machado de Assis.

Quando solicitamos essa produção textual não havíamos explicado como fazê-la, pedimos para que desenvolvessem em sala, tendo como base o conhecimento que já tinham sobre o que era resumir um texto. Ao agenciar a atividade dessa maneira, a pesquisadora teve como objetivo compreender qual a ideia sobre resumo que os alunos tinham. $\mathrm{O}$ desenvolvimento da produção textual em sala possibilitou avaliar de fato o conhecimento sobre o gênero resumo, tendo em vista a impossibilidade de o aluno pesquisar acerca de como fazer um resumo. Sendo assim as condições de produção do resumo foram:

Nesse aspecto, tivemos as seguintes condições de produção:

Produção textual, a partir de solicitação da professora, no $1^{\circ}$ dia de aula, sem indicação de tema ou gênero.

Lugar social de onde se fala: ingressantes do $1^{\circ}$ período do curso de Direito

Função social do locutor: aluno do $1^{\circ}$ período do curso de Direito

Função Social do interlocutor: professora de Língua Portuguesa textual.

Objetivos da interação verbal: identificar as dificuldades no processo de produção

A 2 aPT solicitada foi o resumo do conto "Pai contra mãe" de Machado de Assis.

Quando solicitamos essa produção textual não havíamos explicado como fazê-la, pedimos para que desenvolvessem em sala, tendo como base o conhecimento que já tinham sobre o que era resumir um texto. Ao agenciar a atividade dessa maneira, a pesquisadora teve como objetivo compreender qual a ideia sobre resumo que os alunos tinham. $\mathrm{O}$ desenvolvimento da produção textual em sala possibilitou avaliar de fato o conhecimento sobre o gênero resumo, tendo em vista a impossibilidade de o aluno pesquisar acerca de como fazer um resumo. Sendo assim as condições de produção do resumo foram: 
Texto base: conto "Pai contra mãe" de Machado de Assis.

Texto a ser desenvolvido pelo aluno: resumo do respectivo conto.

Lugar social de onde se fala: $1^{\circ}$ período do curso de Direito.

Função social do locutor: aluno do $1^{\circ}$ período do curso de Direito.

Função Social do interlocutor: professora de Língua Portuguesa do curso.

Objetivos da interação verbal: identificar as representações e conhecimentos trazidos pelos alunos sobre o gênero resumo.

A $3^{\text {a }}$ PT produzida consistiu na reescrita do resumo, mas, antes de solicitá-la, foram trabalhados alguns capítulos do livro "Resumo" das autoras Machado, Lousada, AbreuTardelli (2004), sendo eles: Sumarização: processo essencial para a produção de resumos; A compreensão global do texto a ser resumido; A localização e explicitação das relações entre as ideias mais relevantes do texto e Atribuição de atos ao autor do texto resumido. Os alunos leram os materiais em casa e fizeram os exercícios do livro. Em sala, expusemos sobre todos esses processos apresentados pelas autoras e corrigimos os exercícios.

A escolha da obra das autoras se deu pelo fato de ela apresentar uma exposição acerca da produção de textos com objetivo de síntese e apresentar atividades de modo processual e didático. Os exercícios possibilitaram aos alunos o desenvolvimento do raciocínio crítico, pois, à medida que íamos corrigindo, eles diziam: "O resumo que entreguei para a senhora está errado, vou perder muito ponto". Esse reconhecimento é muito interessante, pois o aluno consegue assumir o papel de sujeito agente apropriando-se de conhecimentos e tornando-se um crítico do seu próprio texto.

Após a correção dos exercícios, pedimos aos alunos que expusessem sobre o que era resumo para eles. Depois da exposição, orientou-se para que trocassem o seu resumo com o colega, com o objetivo de um avaliar o texto do outro. Para essa avaliação, foi apresentado o seguinte quadro de critérios:

Há menção ao autor do texto resumido?
O colega contextualizou a obra?
O resumo do colega está de acordo com o texto original?
O resumo apresenta-se coeso e coerente?
Tem informações (des) necessárias?
Você, como leitor do texto do colega, conseguiu compreender a obra de Machado
de Assis apenas lendo o resumo?

Após a atividade de avaliação conjunta, cada um retomou o seu texto, para, em casa, reescrever seu resumo e entregá-lo no prazo de uma semana. 
Research, Society and Development, v. 7, n. 7, p. 01-28, e1577360, 2018

ISSN 2525-3409 (CC BY 4.0)

Cabe salientar que, antes da reescrita, analisamos o conto juntos. Iniciamos o processo de contextualização da obra, ano em que foi publicada, qual foi o contexto histórico da época e os principais aspectos do conteúdo temático. Foi dado espaço para que os alunos fizessem seus comentários. As condições de produção estabelecidas aos alunos para desenvolvimento da reescrita foram:

Reescrita do resumo do conto "Pai contra mãe" de Machado de Assis.
Lugar social de onde se fala: $1^{\circ}$ período do curso de Direito.
Função social do locutor: acadêmico do curso de Direito.
Função Social do interlocutor: aluno do curso de sociologia.
Objetivos da interação verbal: identificar e analisar o comportamento humano no
período da escravidão no Brasil.

A $4^{\mathrm{a}}$ PT foi a resenha do filme "O leitor". Contudo, antes de requerer o texto, foi explicado em sala como se escreve uma resenha.

Inicialmente utilizamos como base para a explicação do que é uma resenha a obra de Désirée Motta-Roth e Graciela Rabuske Hendges (2010) que explicam a resenha da seguinte maneira:

A resenha é um gênero discursivo em que a pessoa que lê e aquele que escreve têm objetivos convergentes: uma busca e a outra fornece uma opinião crítica sobre determinado livro. Para atender ao leitor, o resenhador basicamente descreve e avalia uma dada obra a partir de um ponto de vista informado pelo conhecimento produzido anteriormente sobre aquele tema. (2010, p. 28).

A abordagem desenvolvida pelas autoras mostra que, para o gênero resenha, é necessário um desenvolvimento crítico do autor em que se apresentem os seguintes movimentos: apresentar o que está sendo resenhado, descrever, avaliar e recomendar ou não o livro. Esses movimentos, apontados pelas autoras, estabelecem algumas características da resenha, o que a diferencia de outros gêneros, como por exemplo, o resumo.

Após a explicação do funcionamento e das finalidades da resenha, pedimos que os alunos assistissem ao filme "O leitor" e desenvolvessem uma resenha em que abordassem a questão do analfabetismo, relacionando-o com o analfabetismo no Brasil. Para o desenvolvimento dessa resenha estabelecemos as seguintes condições de produção:

Lugar social de onde se fala: instituição de Ensino Superior
Função social do locutor: acadêmico do curso de Direito
Função Social do interlocutor: professores, alunos e demais funcionários da
instituição.
Objetivos da interação verbal: mostrar a relação que há entre ficção e realidade no
que diz respeito ao analfabetismo.
Possível meio de veiculação da resenha: site da instituição e o informativo do curso
de Direito.


Foi dado um prazo de 15 dias para o desenvolvimento da resenha.

A $5^{\text {a }}$ PT foi a reescrita da resenha do filme "O leitor". Para a correção dessa produção levamos em consideração os seguintes aspectos:

Apresentação da obra resenhada.
Explicitação dos objetivos que levaram a desenvolver a resenha.
Relação estabelecida entre o filme e a realidade, no que tange ao analfabetismo
no Brasil.
Conexão entre os parágrafos e as ideias.
Posicionamento autoral do aluno.
Apresentação de sua tese.
Argumentos que sustentam sua tese.
Coerência da conclusão em relação ao que foi exposto no decorrer do texto.

Após corrigir a resenha, ela foi entregue à turma. Os alunos foram orientados a sentar em duplas e trocar as resenhas entre si. Juntos, fizemos uma análise dos principais aspectos de uma resenha abordados no livro "Resenha" (MACHADO, LOUSADA, ABREU-TARDELLI, 2004). Trabalhamos com os capítulos: O plano global de uma resenha acadêmica (prototípica); os mecanismos de conexão: o uso dos organizadores textuais; Procedimento de inserção de vozes: diferentes formas de menção ao dizer do autor do texto resenhado e de outros autores; O diário de leitura: ferramenta para uma leitura crítica do texto. Este último capítulo demonstrava a importância do registro das leituras feitas de modo reflexivo, extremamente necessário para a confecção da resenha temática.

Mostramos também que o diário de leitura não serve apenas para a disciplina de língua portuguesa, mas para todas as outras, pois funciona como orientação para os alunos que possuem dificuldades de leitura dos textos acadêmicos. Em síntese, ao trabalhar com esses capítulos, objetivávamos levar para os alunos uma compreensão mais detalhada do fazer de uma resenha. Como o livro possui exercícios, o entendimento desse gênero poderia ser mais produtivo.

Posteriormente à discussão, foi pedido a cada dupla que lesse a resenha do colega e fizesse sugestões e elogios, no que diz respeito à estrutura, aos elementos enunciativos, à relação do texto com o objetivo que foi apresentado, à clareza ao apresentar as ideias e aos elementos argumentativos que sustentam a produção. Em seguida, os discentes iniciaram o trabalho de reescrita em sala, mas, em função do tempo, terminaram os textos em casa e entregaram na aula seguinte. As condições de produção da reescrita da resenha foram: 
Lugar social de onde se fala: instituição de Ensino Superior.

Função social do locutor: acadêmico do curso de Direito.

Função Social do interlocutor: acadêmico do curso de Letras.

Objetivos da interação verbal: mostrar a relação que há entre ficção e realidade no que diz respeito ao analfabetismo. de Direito.

Possível meio de veiculação da resenha: site da instituição e o informativo do curso

A $6^{\mathrm{a}}$ PT consistiu na produção de uma resenha temática. Propusemos dois temas, e os alunos escolheriam um para desenvolver a resenha. A primeira opção foi uma resenha temática dos filmes "O leitor", "Central do Brasil" e da crônica "Analfabetismo" de Machado de Assis. A resenha deveria se centrar na temática "O analfabetismo no Brasil". A segunda opção, a partir do conto "Pai contra mãe" de Machado de Assis e da reportagem da revista Veja "Vidas estilhaçadas", publicada em 1999, era o desenvolvimento da seguinte temática: "Escravidão x Liberdade: Marcas do passado que refletem no presente".

Ao levarmos o gênero reportagem para a sala, tivemos como objetivo fazer com que os alunos conseguissem compreender o gênero conto que, pela predominância de elementos discursivo-textuais e enunciativos, parece pertencer à ordem do NARRAR ${ }^{2}$, em oposição à reportagem que está para a ordem do EXPOR. Fazer com que o aluno estabelecesse uma relação entre os dois textos foi o nosso principal objetivo. Para o desenvolvimento da resenha temática, foi entregue aos alunos o seguinte roteiro:

\section{Planejamento para a produção de uma resenha temática}

\section{PENSE:}

\section{$1^{\text {a }}$ Etapa}

- Qual função social que irei assumir no processo de produção do meu texto?

- Qual a função social do leitor real do meu texto?

- Qual a função social do leitor projetado para ler o meu texto?

- Qual o conteúdo temático do meu texto?

- Qual pano de fundo sustentará o meu texto? (Contexto socioistórico)

- Quais obras serão "analisadas"?

- Qual a relação que há entre as obras?

- Qual o objetivo do meu texto?

\footnotetext{
${ }^{1}$ Disponível em: http://veja.abril.com.br/240399/p 044.html

2 Essa relação entre a ordem do NARRAR e a ordem do EXPOR é apresentada por Bronckart (2006), também chamada de Mundos Discursivos, em que o NARRAR pertence à ficção e, por isso, é considerado disjunto à nossa realidade e o EXPOR pertence à 'realidade', estando conjunto ao nosso mundo ordinário.
} 
- Quais as condições de produção do meu texto?

\section{$2^{\text {a }}$ Etapa}

Após a etapa do planejamento, inicia-se o processo de pesquisa bibliográfica que irá sustentar sua resenha.

- A pesquisa deverá corresponder a seu processo de planejamento.

- Após a definição do conteúdo temático é importante a sua delimitação, assim, a pesquisa será mais centrada no que de fato você precisa;

- Faça fichamentos, resumos do que foi pesquisado;

- Avalie a relevância do que se pesquisou para a sua resenha;

- Certifique-se de a pesquisa dará suporte a seus objetivos;

\section{$3^{\text {a }}$ Etapa}

\section{Após o processo de pesquisa, inicia-se o processo de escrita da Resenha.}

\section{Mãos à obra}

- Lembre-se de que a resenha deve ser feita com um olhar crítico

- Crie um título chamativo;

- Faça uma apresentação do que será resenhado;

- Deixe claro como será desenvolvido o seu texto;

- No processo de desenvolvimento de sua resenha descreva as obras em análise;

- Desenvolva a sua avaliação;

- Estabeleça a relação entre as obras, é necessário que elas estejam interligadas no corpo do texto.

- Organize o seu texto por meio de elementos de conexão;

- Pense em como será a sequência de ideias;

- Não se esqueça de colocar as referências bibliográficas

- Identifique-se

\section{$4^{\text {a }}$ Etapa}

\section{Processo de Leitura e reescrita da Resenha}

- Após escrever sua resenha, releia;

- Certifique-se de que o que foi planejado está de fato sendo desenvolvido em seu texto;

- Pense no seu leitor projetado, ele irá compreender de forma clara qual a sua intenção ao produzir a resenha?

- Releia o texto e o "enxugue". Retire tudo o que estiver repetitivo;

- Os seus objetivos foram alcançados?

- Ele está claro? Coeso? Coerente?

- Solicite a alguém a leitura do seu texto. Essa leitura deverá se ater aos seguintes critérios: a resenha atende aos objetivos propostos? Apresenta a obra? Divulga e/ou recomenda (ou não)?

- Finalize o texto 
Research, Society and Development, v. 7, n. 7, p. 01-28, e1577360, 2018

ISSN 2525-3409 (CC BY 4.0)

Este roteiro foi criado a partir do que Bronckart (1999, p.93) concebe como "contexto de produção", tendo em vista que este influencia a organização do texto, sendo ele constituído pelo conjunto do mundo físico, social e subjetivo. Utilizamos também como base o que Machado, Lousada e Abreu-Tardelli (2004) chamam de "diário de leitura" em que fazem apontamentos de como fazer uma leitura crítica de um determinado texto.

Cada item do roteiro foi explicado. Para a execução da resenha, deu-se um prazo de 25 dias, percurso temporal em que a turma seguiria operando com seus conhecimentos na produção de outros textos do domínio acadêmico.

Para a execução da resenha, orientamos que os acadêmicos se reunissem em grupos, assistissem aos filmes e discutissem a respeito. Com relação à segunda opção da resenha temática, fizemos um debate em sala, relacionando o conto com a reportagem. No curso do debate, demandou-se que os alunos buscassem subsídios nas disciplinas dos outros professores do período, assim, eles começaram a apontar os aspectos apreendidos nas matérias e a relação que eles tinham com a temática proposta. Esse debate foi a primeira produção oral em sala de aula. As condições de produção para a construção da resenha temática foram:

Lugar social de onde se fala: instituição de Ensino Superior.
Função social do locutor: acadêmicos do curso de Direito.
Função Social do interlocutor: professores, alunos e demais interessados sobre a
temática abordada.
Objetivos da interação verbal: desenvolver uma análise crítica de obras/textos
variados que fazem uma abordagem da mesma temática.
Possível meio de veiculação da resenha: site da instituição e o informativo do curso
de Direito.

A $7^{\text {a }}$ PT e última produção escrita foi o desenvolvimento de um artigo de opinião. Precisamos aqui justificar o porquê da escolha do artigo de opinião, visto que este é um gênero do domínio jornalístico, não sendo, portanto, considerado como um gênero pertencente à esfera acadêmica. Primeiramente cabe ressaltar que este trabalho foi desenvolvido com o objetivo de que o aluno fosse capaz de desenvolver práticas letradas do universo acadêmico, sem preocupação com a rotulagem de gêneros em si mesmos. Em segundo lugar, a ideia da produção do artigo de opinião originou-se da necessidade de apreender com mais clareza a exposição dos pontos de vista dos acadêmicos. Sendo assim, este gênero, para os objetivos da disciplina ministrada, assume maior relevância, por permitir ao acadêmico o desenvolvimento crítico e maior posicionamento autoral. $\mathrm{O}$ aluno, quando se 
torna sujeito agente do seu dizer, mobiliza com mais segurança o seu dito, isto é, explicita mais claramente o seu posicionamento enunciativo.

Antes do desenvolvimento do artigo levamos para a sala dois artigos de opinião e juntamente com os alunos levantamos as características mais salientes do artigo. Em seguida, apresentamos alguns apontamentos feitos por Marcuschi (2008) sobre esse gênero. Antes de desenvolver o artigo de opinião, o aluno, em grupo, desenvolveu um trabalho multidisciplinar ${ }^{3}$. As condições de produção para a elaboração do artigo foram:

Lugar social de onde se fala: instituição de Ensino Superior.
Função social do locutor: cidadão, acadêmico do curso de Direito.
Função Social do interlocutor: cidadãos, alunos e demais interessados sobre a
temática abordada.
Objetivos da interação verbal: tecer uma posição crítica sobre a temática trabalhada
no seminário interdisciplinar.
Possível meio de veiculação da resenha: jornal da instituição e informativo do curso
de Direito.

É preciso salientar que todas as PT eram corrigidas e entregues aos alunos, não só para os colaboradores desta pesquisa, mas a todos os alunos. Ao avaliar as produções, fazíamos apontamentos no corpo do texto, identificando os problemas e tecendo algumas orientações. Em seguida projetávamos algumas produções no quadro e, juntos, desenvolvíamos uma análise de forma explicitar os aspectos positivos e negativos.

Quando pensamos em uma maneira de promover o desenvolvimento dos alunos nas práticas discursivas do meio acadêmico, não pensamos em alterar apenas a didática da PP, mas também atrelá-la às outras disciplinas. Como o próprio título desta pesquisa diz, é uma proposta multidisciplinar de práticas integradas, ou seja, trata-se de, juntamente com os outros professores, desenvolver atividades comuns em que os estudantes consigam estabelecer relações entre uma disciplina e outra em função de um objetivo comum.

A nossa proposta foi a seguinte: cada aluno escolhia o tema que queria trabalhar, em seguida o professor escolhia o grupo, relacionando a sua disciplina ao tema ${ }^{4}$ escolhido. Após cada grupo já ter um professor orientador, foi proposto que eles desenvolvessem um questionário a respeito da sua temática e fossem a campo fazer aplicar o questionário. A

\footnotetext{
${ }^{3}$ Para Minayo (2002, p.436), multidisciplinar consiste em uma justaposição de disciplinas em que cada uma com suas teorias e metodologias tem uma visão do mesmo de forma a contribuir com diversas perspectivas.

${ }^{4}$ Os temas abordados foram: Redução da Maioridade Penal; Investimentos X Desigualdades; Eutanásia; Aborto de fetos anencéfalos; Educação Inclusiva; Cotas Raciais X Cotas Sociais.
} 
escolha de quem ia ser entrevistado ficou a critério do grupo. Dando sequência, fizeram o levantamento dos dados e construíram os gráficos. Com os dados em mãos os acadêmicos delimitaram ainda mais o tema para fazer a apresentação, frisando sempre a relação existente entre as disciplinas envolvidas e o professor que os orientava.

As apresentações dos trabalhos integraram um seminário no auditório da faculdade. Orientamos os alunos a respeito da adequação da linguagem ao contexto, do vestuário, da linguagem corporal e da utilização da norma padrão da língua.

No dia das apresentações, cada grupo teve 25 minutos para poder apresentar a pesquisa e as questões por eles abordadas. A ideia inicial era que no dia da apresentação de cada grupo o professor orientador estivesse presente, pois, se alguém fizesse uma pergunta e os alunos não soubessem responder, o professor responderia. No entanto, nem todos puderam comparecer no dia.

As apresentações foram excelentes e o que mais surpreendeu os alunos e alguns professores foi a pesquisa de campo, a entrevista, pois a visão que se tem hoje das pesquisas dentro do Direito é que elas correspondem apenas à revisão bibliográfica. Portanto, as entrevistas foram fundamentais. Alguns grupos entrevistaram os próprios colegas do Direito que já estavam em períodos mais avançados, e ficaram surpresos por muitos deles não saberem responder a determinada pergunta ${ }^{5}$ que integrava o questionário.

Durante as apresentações, alguns alunos conseguiram relacionar as matérias à temática abordada, como foi o caso de "R", cujo grupo expôs sobre Eutanásia. O professor que orientou o grupo do "R" leciona a disciplina de Introdução ao Estudo de Direito.

Segue abaixo uma parte da entrevista com os alunos que ilustra o que foi dito acima:

Aluno "R" - "Interessante que a gente conseguia ver as disciplinas, igual o nosso trabalho mesmo "Eutanásia" a gente via a questão da política, legalização, a questão e ... da matéria do "D", a do Estado em envolver na morte do paciente, a questão do da ciência política também, sociologia, a filosofia da vida e da morte, tudo, tudo tudo/[ ]"

A apresentação do seminário envolveu os alunos do $1^{\circ}$ e $2^{\circ}$ períodos.

Como sequência do trabalho, os alunos produziram um artigo de opinião a respeito do tema por eles abordado, e assim tivemos a $7^{\mathrm{a}} \mathrm{PT}$ e última produção textual escrita.

Pelo fato de a pesquisa se embasar no fazer docente e ser aplicada e implicada, levamos para a sala de aula o documentário "À margem do corpo"6. Como no primeiro debate

${ }^{5}$ Exemplo: Pergunta feita por determinado grupo: Você sabe diferenciar Eutanásia de Ortotanásia?
Muitos estudantes do $10^{\circ}$ período de Direito não souberam responder.

${ }^{6}$ Disponível em: http://vimeo.com/6117113 
feito em sala os alunos mostraram-se mais participativos, compreendemos que finalizar as atividades do semestre com o debate desse documentário permitiria que desenvolvessem mais suas habilidades de análise discursiva-textual.

Para o desenvolvimento do debate, abordamos alguns aspectos relacionados à argumentação que estão detalhados no capítulo teórico ${ }^{7}$. A turma foi dividida em dois grupos, sendo que um iria defender a mãe que matou sua filha, e o outro iria acusá-la. Cabe dizer que o documentário possibilita a elaboração de argumentos a ambos os grupos. Foi dado um prazo de 10 dias para que os grupos pudessem se organizar para essa apresentação. Para o debate, eles procuraram os professores, inclusive a professora de Direito Penal que não ministra aulas para no $1^{\circ}$ período. Essa interação entre discente e docente em torno de objetivos é extremamente significativa para o desenvolvimento acadêmico e profissional do sujeito, pois, assim como o trabalho multidisciplinar, o debate demandava ativação de muitos saberes cruzados, que começavam a ser construídos pelos alunos.

Para ilustrar a relevância desses trabalhos, traremos parte da entrevista do $\mathrm{GF}^{8}$ em que os alunos falam a respeito do debate.

\footnotetext{
Aluno - "G" - o debate, NOOOSSA foi excelente, ao meu ver, mas é é e eu acho também que podia dar mais debates igual aquele que você deu. É muito bom, porque gente que nem abre a boca na sala falou...sem contar que o ponto que você não viu outra pessoa viu
}

Aluno - "E" O debate foi um máximo a gente pode interagir, que era uma coisa que ninguém acreditava, que quem tava na defesa queria saber o que a acusação ia falar e a mesma coisa...

Aluno - "A" - [...] Aqui tipo assim igual o debate que teve,assim, pra mim custo me abrir muito entendeu eu acho que esse trabalho ótimo entendeu pelo menos para mim que custo me abrir entendeu a gente vai conhecendo igual foi falado aqui entendeu, o argumento (confuso) faz a gente questionar, faz a gente buscar então eu acho que deveria ser mais trabalhado. Então tipo assim, eu acho que eu melhorei bastante entendeu vou para com esse entendeu TÁ PP. (risos) eu melhorei bastante e esses trabalhos entendeu (risos) e com os trabalhos eu consegui perceber por mim mesma assim que eu melhorei bastante, as minhas escritas aaaaa forma de de de enxergar, ah outra coisa

\footnotetext{
7 No capítulo teórico buscamos sustentação em estudos de autores que tratam dos aspectos que promovem a argumentação.

8 Para a transcrição do grupo focal adaptamos o quadro de transcrição apresentado por Castilho (2004, p. 34-35), em que temos o seguinte:

Incompreensão de palavras ou segmentos $=($ );

Hipótese do que se ouviu = (hipótese);

Entoação enfática = MAIÚSCULAS;

Alongamento de vogal ou consoante = ::;

Pausa $=\ldots$;

Comentários descritivos $=(($ minúsculas $))$;

Superposição, simultaneidade de vozes = [ ligando linhas;

Truncamento = $/$

Gesticulação = @
} 
Aluno - "P" - a parte do debate também, por mais que eu não tenha participado eee por eu estar ouvindo, eee eu achei muito bom e,,, é,,, aluno discutindo é conforme as diferentes variáveis, então eu achei muito bacana...

Resta assinalar que, durante as atividades propostas para o desenvolvimento desta pesquisa, tivemos o apoio de todos os professores, inclusive dos que não lecionavam para $\mathrm{o} 1^{\circ}$ período. Eles contribuíram muito para o desenvolvimento dessa proposta de trabalho. Os alunos do $1^{\circ}$ período, ao longo do semestre, produziram muitos textos e debates em outras disciplinas. Eles fizeram uma resenha do livro "Ética para meu filho" de Fernando Savater, participaram de debates da turma do $10^{\circ}$ período e depois, a pedido do professor, desenvolveram uma resenha. Outro professor sugeriu como atividade uma análise crítica de uma determinada matéria jornalística, à escolha do aluno. Vários resumos foram produzidos ao longo do semestre, embora eu não tenha participado efetivamente da avaliação desses textos, condição essencial para o êxito de um trabalho compartilhado e multidisciplinar.

Por fim, podemos dizer que um trabalho inter/multidisciplinar faz toda a diferença na formação dos alunos, pois permite a eles estabelecer um diálogo entre as disciplinas e um desenvolvimento autoral e crítico.

\section{Cconsiderações finais.}

Antes de desenvolver esta pesquisa, muito já havia sido pensado sobre as dificuldades dos alunos com práticas de leitura e produção textual na graduação. Em relação a nossas ações didáticas com práticas de linguagem, começamos a nos questionar: como desenvolver uma metodologia de trabalho com leitura e produção de textos que leve de fato ao desenvolvimento letrado dos estudantes ingressantes no curso de Direito? Foi a partir dessa pergunta que objetivamos investigar e analisar formas de promover, por meio de práticas integradas e transdisciplinares, as capacidades de leitura e escrita do domínio acadêmico do futuro bacharel em Direito. Consideramos que, a partir do momento em que os professores passaram a dialogar entre si e buscaram desenvolver atividades em conjunto, foi possível promover habilidades de textualização (escrita e oral) e de uso dos recursos textuais e discursivos pelos alunos e estimular a participação desses estudantes nas mais variadas práticas discursivas.

Portanto, por meio da pesquisa-ação, foi possível desenvolver uma pesquisa aplicada e implicada, orientada pelo viés da multidisciplinaridade, que permitisse ampliar as práticas de letramento acadêmico dos graduandos. Partimos da hipótese de que há uma relação entre 
os modos de orientação de cada professor em sua disciplina com o desenvolvimento de habilidades de leitura e produção textual do acadêmico. Além disso, acreditamos que a mudança de metodologia à luz de uma abordagem interacionista e sociodiscursiva de desenvolvimento possibilitou uma transformação nos modos como os estudantes compreendem e usam a língua e a linguagem dentro do universo acadêmico. Nesse sentido, a metodologia de trabalho com as práticas textuais no curso de Direito, em que os sujeitos acadêmicos fossem de fato agentes de seus discursos, permitiu ampliar as capacidades linguageiras desses estudantes no que se refere às habilidades de leitura e escrita.

A partir das análises das produções textuais desenvolvidas pelos acadêmicos ao longo da pesquisa, confirmamos que atividades interdisciplinares e práticas que promovam o letramento acadêmico, como as atividades de retextualização, reescrita, debates e seminários possibilitaram o desenvolvimento crítico e autoral dos alunos. É possível dizer que os graduandos, desde a primeira produção textual até última, participaram ativamente dos processos reflexivos que os levariam a se apropriar dos modos de produzir um texto. Eles saíram da condição de reprodutores de um dizer em que predomina o senso comum, para se posicionarem como sujeitos agentes do processo discursivo. Não estamos aqui negando que muitas dificuldades ainda persistem, principalmente, as relacionadas à microestrutura, e que elas também precisam ser trabalhadas, mas não podemos permitir que essas dificuldades neutralizem o fazer discursivo dos alunos.

Podemos dizer que as práticas multidisciplinares e transdisciplinares são a chave para o desenvolvimento do letramento acadêmico do aluno. Essas práticas permitem que professores e alunos vislumbrem a construção de um saber científico ancorado em uma via de mão dupla que contribui não somente para o desenvolvimento linguístico-textual dos discentes, mas sobretudo para a constituição de um saber fazer necessário no meio acadêmico.

Por fim, é preciso dizer que chegamos a esta conclusão porque desenvolvemos uma pesquisa com os alunos, uma pesquisa-ação aplicada e implicada em que, a cada dado observado e a cada etapa vivenciada, modificávamos a nossa forma de lecionar. Não é possível compreender a complexidade do ensino e do letramento acadêmico a partir de suposições, resultados de avaliações e dados estatísticos, mas a partir de uma interação com os alunos, pois são eles que nos fornecem todos os dados e que orientam o nosso fazer docente. Não podemos desconsiderar as condições de mobilização demonstradas pelos estudantes, no processo da aprendizagem, em sala de aula, portanto, é importante 


\section{Research, Society and Development, v. 7, n. 7, p. 01-28, e1577360, 2018}

ISSN 2525-3409 (CC BY 4.0)

reconhecermos que novas formas de pesquisar se fazem necessárias porque, somente assim, conseguiremos perceber que o nosso agir faz toda a diferença.

\section{Referências}

ASSIS, Juliana Alves; MATA, Maria Aparecida. A escrita de resumos na formação inicial do professor de Língua Portuguesa: movimentos de aprendizagem no espaço de sala de aula. In: KLEIMAN, Angela B.; MATENCIO, Maria L. M. (Orgs.). Letramento e formação do professor: práticas discursivas, representações e construção do saber. Campinas, SP: Mercado de Letras, 2005. p. 1-18.

ASSIS, Juliana. A. Eu sei mas não consigo colocar no papel aquilo que eu sei: representações sobre os textos acadêmico-científicos e pistas para a didática da escrita na universidade. In : ASSIS, J. A.; BOCH, F.; RINCK, F. (Org.). Letramento na universidade. Campinas: Mercado de Letras, 2012. p. 3.

ASSIS, Juliana Alves; MATA, Maria Aparecida da; PERINI-SANTOS, Pedro.

Ensino/aprendizagem de resumos acadêmicos em sala de aula : negociação de representações. In: ENCONTRO INTERNACIONAL LINGUAGEM CULTURA E COGNIÇÃO: Reflexões para o Ensino, 2, 2003, Campinas. Anais... Campinas, São Paulo: Graf. FE; ALB, 2003. p. 115 .

AUTHIER-REVUZ, J. A. Não-coincidência interlocutiva e seus reflexos metaenunciativos In: Entre a transparência e a opacidade: um estudo enunciativo do sentido. Porto Alegre: EDIPUCRS, 2004.

BARBIER, René. A pesquisa-ação. Tradução Lucie Didio. Brasília: Plano, 2002.

BAKHTIN, Mikhail. Estética da criação verbal. 3. ed. São Paulo: Martins Fontes, 2000.

BAKHTIN, M./VOLOCHINOV, L. Marxismo e filosofia da linguagem. 2. ed. São Paulo: Hucitec, 1981.

BAKHTIN, M./VOLOCHINOV, L. Marxismo e filosofia da linguagem. 7. ed. São Paulo: Hucitec, 1995.

BORTONI-RICARDO, Stella Maris. O professor pesquisador: introdução à pesquisa qualitativa. São Paulo: Parábola, 2008.

BRETON, Philippe. A argumentação na comunicação. São Paulo: Edusc, 2003.

BRONCKART, Jean- Paul. Atividade de linguagem, textos e discursos: por um interacionismo sócio-discursivo. São Paulo: EDUC, 1999.

BRONCKART, Jean-Paul. Atividades de Linguagens, texto e discursos:por um interacionismo sócio-discursivo. Trad. Anna Rachel Machado e Péricles Cunha. São Paulo: Educ, 1997/99. 
BRONCKART, Jean- Paul. Atividade de linguagem, discurso e desenvolvimento humano. Campinas: Mercado de Letras, 2006.

BRONCKART, Jean- Paul. Atividade de linguagem, textos e discursos: por um interacionismo sócio-discursivo. 2.ed. São Paulo: EDUC, 2007

CHAPOULIE, Jean Michel. Everett C. Hughes et le developpement du travail de terrain en France. Revue Française de Sociologie, v. 25, n. 4, 1984, p. 582-608.

CORRÊA, Manoel Luiz G.; BOCH, Françoise (Org.). Ensino de língua: representação e letramento. Campinas, São Paulo: Mercado das Letras, 2006.

DELL'ISOLA, Regina Lúcia Péret. Retextualização de gêneros escritos. Rio de Janeiro: Lucerna, 2007.

DUCROT, Oswald. O dizer e o dito. Campinas, SP: Pontes, 1987.

EMEDIATO, Wander. A fórmula do texto: redação, argumentação e leitura. São Paulo: Geração Editorial, 2008.

GARCEZ, Lucília Helena do Carmo. Técnica de redação: o que é preciso saber para bem escrever. São Paulo: Martins Fontes, 2012.

GILLY, M. Les représentations sociales dans le champ éducatif. In. JODELET, D. Les représentations sociales: un domaine en expansion. Paris: Presses Universitaire de France, 1989.

JODELET, Denise.Les représentations sociales: un domaine en expansion. In JODELET, D. Les représentations sociales: un domaine en expansion. Paris: Presses Universitaire de France, 1989.

JUNIOR FERRAZ, Tércio Sampaio. Direito, Retórica e Comunicação: subsídios para uma pragmática do discurso jurídico. São Paulo: Saraiva, 1997.

KATO, Mary Aizawa. No mundo da escrita: uma perspectiva psicolinguística. São Paulo: Ática, 1986.

KLEIMAN, Angela B. Os significados do letramento: uma nova perspectiva sobre a prática social da escrita. Campinas, São Paulo: Mercado das Letras, 1995.

KLEIMAN, Angela B. Modelos de letramento e as práticas de alfabetização na escola.In: KLEIMAN, Angela B. (Org.). Os significados do letramento. Campinas, São Paulo: Mercado de Letras, 1995.

KLEIMAN, Angela B. Abordagens da leitura. SCRIPTA, Belo Horizonte, v. 7, n. 14, 2004, p. 13-22. 


\section{Research, Society and Development, v. 7, n. 7, p. 01-28, e1577360, 2018}

ISSN 2525-3409 (CC BY 4.0)

KLEIMAN, Angela. Trajetórias de acesso ao mundo da escrita: relevância das práticas não escolares de letramento para o letramento escolar. Perspectiva, Florianópolis, v. 28, n. 2, p. 569-599, jul./dez. 2010.

KOCH, Ingedore Grunfeld Villaça. A inter-ação pela linguagem. São Paulo: Contexto,1997.

KOCH, Ingedore Grunfeld Villaça. Argumentação e Linguagem. São Paulo: Cortez, 2011.

LOPES, Maria Angela Paulino Teixeira. Processos inferenciais de referenciação na perspectiva sócio-discursiva. 2004. 343f. Tese. (Doutorado) Universidade Federal de Minas Gerais, Faculdade de Letras, Belo Horizonte

MACHADO, Anna Rachel; LOUSADA, Eliane; ABREU-TARDELLI, Lílian Santos. Resenha. 2. ed. São Paulo: Parábola, 2004.

MACHADO, Anna Rachel; LOUSADA, Eliane; ABREU-TARDELLI, Lílian Santos. Resumo. São Paulo: Parábola, 2004.

MACHADO, Daniela Zimmermann; PEREIRA Rodrigo Acosta. A infraestrutura textual do gênero Ombudsman: um estudo interacionista sociodiscursivo. Working papers em linguística, Florianópolis, n. especial, p. 127-147, 2009. Disponível em: http://www.periodicos.ufsc.br/index.php/workingpapers/article/view/12735. Acesso em: 15 dez. 2012.

MARCUSCHI, Luiz Antônio. Da fala para a escrita: atividades de retextualização. São Paulo: Cortex, 2001.

MARCUSCHI, Luiz Antônio. Produção textual, análise de gêneros e compreensão. São Paulo: Parábola Editorial, 2008.

MATENCIO, Maria de Lourdes Meirelles. Referenciação e retextualização de textos acadêmicos: um estudo do resumo e da resenha. CONGRESSO INTERNACIONAL DA ABRALIN, 3, 2003, Rio de Janeiro. Anais..., Rio de Janeiro: Associação Brasileira de Linguística, 2003, p.1-11

MATENCIO, Maria de Lourdes Meirelles. Atividades de (re)textualização em práticas acadêmicas: um estudo do resumo. SCRIPTA, v. 6, n. 11. Belo Horizonte: PUC Minas, 2002.

MATENCIO, Maria de Lourdes Meirelles. Gêneros do discurso e apropriação de saberes: (re)conhecer as práticas linguageiras em sala de aula.In: Linguagem em (Dis)curso - LemD, v. 8, n. 3, p.541-562, set./dez. 2008.

MINAYO, Cecília de Souza. O desafio do conhecimento: pesquisa qualitativa em saúde. São Paulo: Hucitec, 1992.

MINAYO, Cecília de Souza (org.). Pesquisa social: teoria, método e criatividade. 25. ed. Petrópolis, Rio de Janeiro: Vozes, 2007. 
MINAYO, Cecília de Souza. O desafio do conhecimento: pesquisa qualitativa em saúde. 9. ed. São Paulo: Hucitec, 2006.

MOSCOVICI, Serge. Representações sociais: investigações em psicologia social. Petrópolis: Vozes, 2003.

MOTTA-ROTH, Désirée, HENDEGS, Graciela Rabuske. Produção textual na

universidade. São Paulo: Parábola Editorial, 2010.

OLIVEIRA, Rosiska Darcy; OLIVEIRA, Miguel Darcy. Pesquisa social e ação educativa. In. Carlos Rodrigues Brandão, (Org.). Pesquisa participante. São Paulo: Brasiliense, 1981.

PLANTIN, Christian. A argumentação: história, teorias, perspectivas. São Paulo: Parábola Editorial, 2008.

RINCK, Fanny; SILVA, Jane Quintiliano Guimarães; ASSIS, Juliana Alves. Qual abordagem erigir para pensar as práticas de leitura e escrita na formação acadêmica e/ou na vida profissional?. Scripta, Belo Horizonte, v. 16, n. 30, p. 7-15, jan./jun. 2012.

SILVA, Jane Quintiliano Guimarães; DA MATA, Maria Aparecida. Proposta tipológica de resumos: um estudo exploratório das práticas de ensino da leitura e da produção de textos acadêmicos. Scripta, Belo Horizonte, v. 6, n. 11, p. 123-133, jul./dez. 2002.

SANTOS, Sandoval Nonato Gomes; SEIXAS, Caroline. Gêneros textuais da formação docente inicial: o projeto de ensino de língua portuguesa. Scripta, Belo Horizonte, v. 16, n. 30, p. 151-168, jan./jun. 2012.

SCHNEUWLY, Bernard; DOLZ, Joaquim. Sequências didáticas para o oral e a escrita: apresentação de um procedimento. In: SCHNEUWLY, Bernard; DOLZ, Joaquim. Gêneros orais e escritos na escola. Campinas, São Paulo: Mercado de Letras, 2004.

SOARES, Magda. Letramento: um tema em três gêneros. Belo Horizonte: Autêntica, 2003.

STREET, Brian V. Literacy in theory and practice. Cambridge, Cambridge University Press, 1984.

TERZI, S.B. A construção do currículo nos cursos de letramento de jovens e adultos não escolarizados. 2006. Disponível em:

http://www.cereja.org.br/arquivos/uploads/sylviaterzipdf>. Acesso em: 24 set. 2012.

TFOUNI, Leda Verdiani. Adultos não alfabetizados: o avesso do avesso. São Paulo: Pontes, 1988.

TRUBILHANO, Fábio; HENRIQUES, Antônio. Linguagem jurídica e argumentação: teoria e prática. São Paulo: Atlas, 2010. 